\title{
Lamellar macular hole surgery - current concepts, future prospects
}

This article was published in the following Dove Medical Press journal: Clinical Ophthalmology

\author{
Christos Haritoglou' \\ Ramin Tadayoni ${ }^{2}$ \\ Jean-Pierre Hubschman ${ }^{3}$ \\ 'Herzog Carl Theodor Eye Clinic, \\ Department of Ophthalmology, \\ Ludwig-Maximilians-University, \\ Munich, Germany; ${ }^{2}$ Department of \\ Ophthalmology, Lariboisière Hospital, \\ Assistance Publique-Hôpitaux de \\ Paris, University Sorbonne Paris Cité, \\ Paris, France; ${ }^{3}$ Retina Division, Stein \\ Eye Institute, University of California \\ Los Angeles, Los Angeles, CA, USA
}

\begin{abstract}
Lamellar macular holes present distinct morphological features including tractional or non-tractional epimacular membranes, foveal tissue alterations, defects of the outer retinal layers, or a separation of the retinal layers. At present, degenerative lamellar holes are differentiated from tractional holes based on the morphological characteristics seen in OCT. The current treatment approach is based on this gross differentiation. Considering the recent developments in high-resolution imaging, this classification needs to be revisited since morphological features may present simultaneously, making it difficult to separate these entities. In addition, a revisited classification may be of value to better standardize the indication for surgical treatment.
\end{abstract}

Keywords: lamellar macular hole, degenerative lamellar hole, tractional lamellar hole, outer retina, lamellar macular hole-associated epimacular proliferation, LHEP

\section{Introduction}

The clinical description of a lamellar macular hole was first reported in 1976 by Donald Gass $^{1}$ who observed a reddish macular lesion in pseudophakic eyes with cystoid macular edema. According to our current understanding, the term lamellar macular hole basically refers to a non-full-thickness defect of the macula, characterized by an irregular foveal contour and a split foveal edge. ${ }^{2,3}$ In some cases lamellar macular holes reveal tissue alterations, which is suggestive of a loss of retinal tissue and consecutive alterations of the foveal morphology. These morphological characteristics differentiate these lesions from full thickness macular holes and macular pseudoholes. ${ }^{2}$ Today, in the era of high-resolution imaging such as spectral domain OCT (SD-OCT), lamellar macular defects are subject to morphological analyses, revealing remarkable and specific characteristics and differences. With improved macular imaging capabilities, it is important to establish an updated classification of these conditions in the future, helping us better characterize various types of lamellar macular holes from a morphological perspective, but also with regard to their (surgical) management.

As to our current understanding, lamellar macular holes are grossly classified into degenerative and tractional lamellar macular holes, although in some cases mixed types of these alterations can be observed. ${ }^{4}$

\section{Tractional lamellar macular hole}

OCT typically reveals a tractional epimacular membrane associated with an elevated foveal edge (Figure 1). The membranes are irregular in shape and retinal adhesion, not always centered with regard to the fovea and often lead to tractional distortion of the inner and the outer retinal layers in more pronounced cases. However, a separation within the retinal layers as a result of traction is almost exclusively seen between the
Correspondence: Christos Haritoglou Herzog Carl Theodor Eye Hospital, Nymphenburger Str. 43, 80335 München, Germany

Tel +49089 1270930

Email christos.haritoglou@

med.uni-muenchen.de
Clinical Ophthalmology 2019:13 |43-|46 


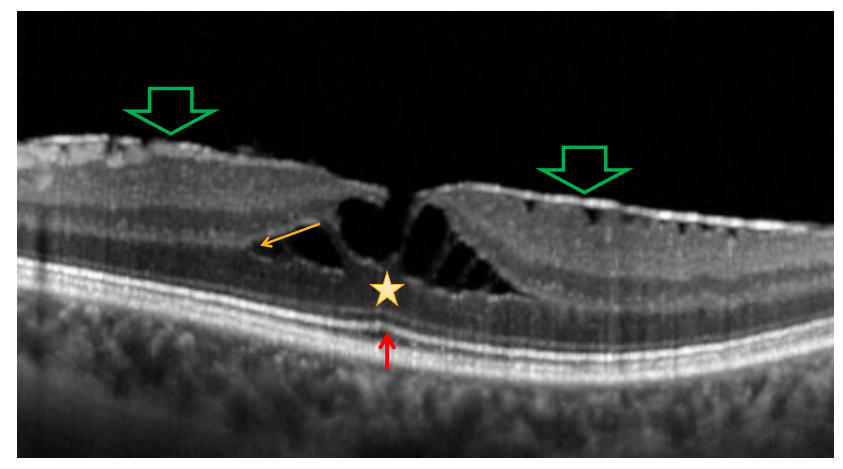

Split between OPL and ONL

No foveal tissue loss $\uparrow$

Ellipsoid zone intact

Figure I A tractional lamellar hole is characterized by tractional epimacular tissue, an elevated foveal edge, and a separation within the retinal layers as a result of traction mostly observed between the outer nuclear and outer plexiform layer. The outer retina is intact in almost all cases.

Abbreviations: ONL, outer nuclear layer; OPL, outer plexiform layer.

outer nuclear and outer plexiform layer and interrupted by vertical hyperreflective structures bridging hyopreflective areas. It was shown that this separation more often occurs in cases with multiple contractile spots in en face OCT. ${ }^{5}$ Intraretinal cystoid changes are sometimes present within the inner plexiform layer. The outer retinal layers, including the ellipsoid zone, are usually not affected. In clinical practice and in the literature, the latter condition is often referred to as a "tractional lamellar macular hole." ${ }^{4}$ Gaudric et al have nicely shown that these cases respond very well to macular surgery. ${ }^{5}$

Degenerative lamellar macular hole (Figure 2) is characterized by wide foveal round-edged intraretinal
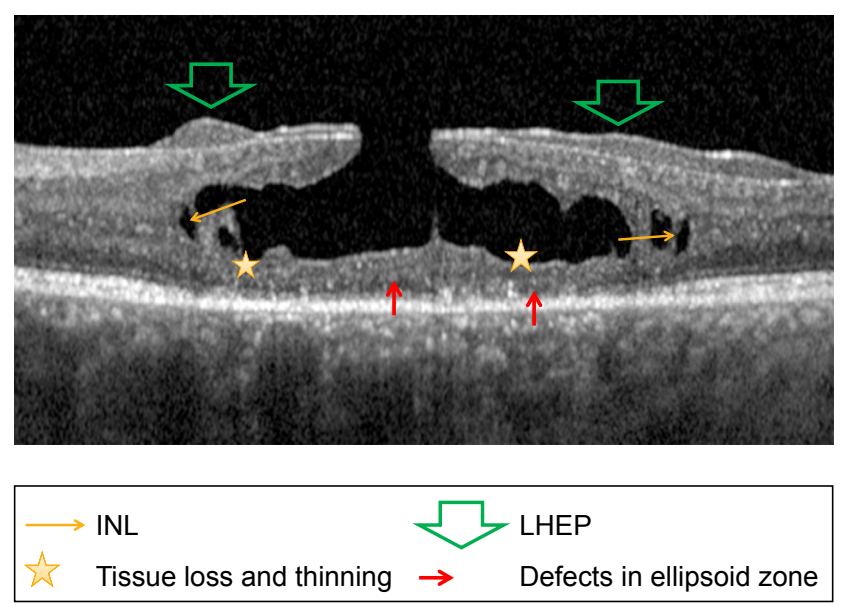

Figure 2 In a degenerative lamellar hole, an intraretinal hyporeflective cavitation is observed.The foveal edges are in general not elevated. Intraretinal alterations may affect all retinal layers including the ellipsoid zone. Often, a peculiar nontractional epimacular tissue with less reflectivity compared to classic epimacular membranes is present.

Abbreviations: INL, inner nuclear layer; LHEP, lamellar macular hole-associated epiretinal proliferation. hyporeflective cavitation without vertical hyperreflective structures as mentioned above. The foveal edges are in general not elevated. Intraretinal alterations may affect all retinal layers including the very outer retinal layers such as the ellipsoid zone. On the retinal surface, often close to the foveal rim, an atypical epimacular tissue may be observed showing less reflectivity compared to classic epimacular membranes, revealing no contractile properties and no areas of hyporeflective space between the proliferation and the inner retina. This tissue is currently referred to as "lamellar macular hole-associated epiretinal proliferation" (LHEP). The presence of a foveal bump can also be seen at the center of the fovea. ${ }^{4,5}$

This current simplified OCT-based differentiation appears practical in daily routine for the indication of surgery, especially concerning the functional improvement that can be expected in the postoperative course. Nevertheless, the current classification needs to be revisited as more precise imaging modalities and clinico-morphological correlations have been recently established. The terminology appears to be even more complex, as a clear separation of the two types of lamellar holes cannot always be achieved since in some cases tractional epimacular membranes and LHEP can be identified simultaneously. ${ }^{6}$

Regarding the management of lamellar macular holes, a standardized therapy or treatment algorithm does not exist. It is important to take into account the subjective complaints of the patient and the evolution of his/her best corrected visual acuity. A surgical intervention is generally more often recommended in the presence of a tractional component including epimacular tissue as seen in pseudoholes with or without intraretinal separation. ${ }^{5}$ Tractional tissue could not always be identified using earlier OCT generations which could explain why surgery was less frequently recommended in cases of lamellar macular holes. ${ }^{2}$ Today, the progress made in the field of high-resolution imaging allows for a far more detailed evaluation and decision-making process concerning surgical therapy and prognosis. The functional result following macular surgery seems to mostly correlate with the type of epimacular tissue and the alteration of the outer retinal layers. In the last few years, a correlation between the integrity of the ellipsoid zone and the functional prognosis after macular surgery for macular holes, pseudoholes, and lamellar macular holes (degenerative type) was demonstrated. ${ }^{7,8}$ A similar correlation between the presence of preoperative outer retinal changes and functional outcomes was made in the presence of LHEP. ${ }^{6}$ Other authors correlated the presence of LHEP with a significant thinning of the bottom and a wider opening of the 
lamellar hole, although without influence on postoperative function. ${ }^{9}$ In contrast, better functional results are obtained in the presence of tractional membranes in association with the lamellar defect. ${ }^{6,10}$ In these cases, alterations of the outer retina are less frequently observed and a removal of the tractional tissue may result in a better restoration of foveal morphology compared to degenerative changes and tissue loss seen in the degenerative LMH. ${ }^{5}$ Coassin et al ${ }^{11}$ very recently published a clinical study on the 36 months followup after surgery for lamellar macular holes. Looking at all patients including all types of lamellar holes, they observed a significant increase of mean best-corrected visual acuity from 20/50 before to 20/33 after surgery. However, when separating different types of lamellar holes, no significant improvement was noted in the subgroup of degenerative lamellar holes $(20 / 81 \text { vs } 20 / 70)^{11}$ in contrast to tractional lamellar holes and mixed types.

An alternative to surgical treatment is the observation of the lamellar defect. It is suggestive to assume that the progression of tractional lamellar holes and degenerative lamellar holes is different. However, OCT-based observational studies $^{12}$ observed the natural course of lamellar macular changes and concluded that these defects may be considered relatively stable conditions regarding functional and morphological criteria when being observed over 18 months. In addition, dell'Omo et al observed a substantial stability of functional and morphologic parameters in nonoperated eyes with tractional epimacular tissue or LHEP alone, or in eyes showing a combination of both types of membranes. ${ }^{13}$ This may be the case even the subgroup of highly myopic eyes, where a functional and morphological stability was described in $60 \%-95 \%$ of cases being observed over 20 or 33 months. ${ }^{14,15}$ However, in this subgroup of patients, eyes with LHEP revealed more damage in the outer retinal layers, lower residual foveal thickness, and a significant reduction of the latter over time, indicating that myopic lamellar macular holes may represent a more severe clinical entity. ${ }^{16}$ Therefore, observation may very well be justified in clinical practice. Nevertheless, the morphological changes should be carefully monitored, since in the long term an increase of the area of LHEP in an eye with a lamellar macular hole may correlate with an enlargement of the lamellar hole diameter and ellipsoid zone defects, ${ }^{17}$ with all of these changes representing negative predictive factors.

Sutureless 23, 25, or 27 gauge pars plana vitrectomy is the standard of care for surgical management of a lamellar macular holes. It was shown in clinico-pathological correlations that in the majority of the cases, vitreous cortex remained adherent to the retinal surface and a complete PVD was infrequent (compared to cases with tractional epimacular membranes without lamellar macular holes). ${ }^{18}$ Therefore, it is important to intraoperatively assure a complete posterior vitreous detachment sometimes using the assistance of triamcinolone crystals. Epimacular membranes can be removed using an end-gripping forceps with or without using staining agents. This can be easily performed in cases of "tractional lamellar holes," since the epimacular tissue can usually be easily identified and is firm. In cases of "degenerative lamellar holes" with LHEP, the removal of epimacular tissue may be more challenging, since LHEP intraoperatively sometimes appears as a yellowish and soft tissue which is often difficult to grasp and separate from the underlying internal limiting membrane (ILM). The differences regarding the tissue rigidity may be explained by distinct cellular components and immunohistochemical variations of these two types of membranes. ${ }^{19}$ However, in both situations, the ILM remains adherent to the retinal surface in most cases and should be removed in a second approach, often following staining. An alternative surgical approach was described by Shiraga et al in $2013^{20}$ who performed a 25 gauge vitrectomy and PVD induction followed by a peeling of epimacular tissue leaving parts of the tissue containing macular pigment adherent to the rim of the lamellar defect. The surgery was finalized by ILM peeling around the lesion, followed by fluid air exchange and face down positioning. Using this technic, the authors achieved a significant visual acuity improvement and a regular foveal contour in $75 \%$ of their cases. According to the authors, the recovery of the outer retina is less likely the result of a photoreceptor regeneration but a glial cell reaction. Although some authors report on the positive effect of a gas fill on postoperative macular morphology, ${ }^{20,21}$ it seems not absolutely necessary to perform a fluid-air exchange to achieve good morphological results in $50 \%$ of cases. ${ }^{22}$ Therefore, postoperative positioning is not routinely recommended.

\section{Summary}

Lamellar macular holes reveal variable morphological aspects. Grossly, some are described as degenerative or tractional conditions, which are associated with specific morphological and functional criteria. With regard to the management of lamellar macular holes, the differentiation of the morphological characteristics with a revisited classification of the different types of LMH is of great relevance as they seem to correlate with the surgical outcomes. Indeed, tractional lamellar holes, which are also considered as a subtype of pseudoholes of the macula, are associated 
with less alterations of the outer retina and seem to respond better to surgery.

Large and prospective investigations are needed to better understand the effectiveness of surgical treatment and ultimately improve the management of these complex macular lesions.

\section{Disclosure}

The authors report no conflicts of interest in this work.

\section{References}

1. Gass JD. Lamellar macular hole: a complication of cystoid macular edema after cataract extraction. Arch Ophthalmol. 1976;94(5):793-800.

2. Haouchine B, Massin P, Tadayoni R, Erginay A, Gaudric A. Diagnosis of macular pseudoholes and lamellar macular holes by optical coherence tomography. Am J Ophthalmol. 2004;138(5):732-739.

3. Witkin AJ, Ko TH, Fujimoto JG, et al. Redefining lamellar holes and the vitreomacular interface: an ultrahigh-resolution optical coherence tomography study. Ophthalmology. 2006;113(3):388-397.

4. Govetto A, Dacquay Y, Farajzadeh M, et al. Lamellar macular hole: two distinct clinical entities? Am J Ophthalmol. 2016;164:99-109.

5. Gaudric A, Aloulou Y, Tadayoni R, Massin P. Macular pseudoholes with lamellar cleavage of their edge remain pseudoholes. Am J Ophthalmol. 2013;155(4):733-742.

6. Schumann RG, Compera D, Schaumberger M. Epiretinal membrane characteristics correlate with photoreceptor layer defects in lamellar macular holes and macular pseudoholes. Retina. 2014;0:1-9.

7. Haritoglou C, Neubauer AS, Reiniger IW, Priglinger SG, Gass CA, Kampik A. Long-term functional outcome of macular hole surgery correlated to optical coherence tomography measurements. Clin Exp Ophthalmol. 2007;35(3):208-213.

8. Hirota K, Itoh Y, Rii T, Inoue M, Hirakata A. Correlation between foveal interdigitation zone band defect and visual acuity after surgery for macular pseudohole. Retina. 2015;35(5):908-914.

9. Lai TT, Chen SN, Yang CM. Epiretinal proliferation in lamellar macular holes and full-thickness macular holes: clinical and surgical findings. Graefes Arch Clin Exp Ophthalmol. 2016;254(4):629-638.
10. Androudi S, Stangos A, Brazitikos PD. Lamellar macular holes: tomographic features and surgical outcome. Am J Ophthalmol. 2009; 148(3):420-426.

11. Coassin M, Mastrofilippo V, Stewart JM, et al. Lamellar macular holes: surgical outcome of 106 patients with long-term follow-up. Graefes Arch Clin Exp Ophthalmol. 2018;256(7):1265-1273.

12. Bottoni F, Deiro AP, Giani A, Orini C, Cigada M, Staurenghi G. The natural history of lamellar macular holes: a spectral domain optical coherence tomography study. Graefes Arch Clin Exp Ophthalmol. 2013; 251(2):467-475.

13. Tanaka Y, Shimada N, Moriyama M, et al. Natural history of lamellar macular holes in highly myopic eyes. Am J Ophthalmol. 2011;152(1): 96-99.

14. dell'Omo R, Virgili G, Bottoni F, et al. Lamellar macular holes in the eyes with pathological myopia. Graefes Arch Clin Exp Ophthalmol. 2018;256(7):1281-1290.

15. Frisina R, Zampedri E, Marchesoni I, Bosio P, Parolini B, Romanelli F. Erratum to: Lamellar macular hole in high myopic eyes with posterior staphyloma: morphological and functional characteristics. Graefes Arch Clin Exp Ophthalmol. 2016;254(11):2141-2150.

16. dell'Omo R, Virgili G, Rizzo S, et al. Role of lamellar hole-associated epiretinal proliferation in lamellar macular holes. Am J Ophthalmol. 2017;175:16-29.

17. Compera D, Schumann RG, Cereda MG, et al. Progression of lamellar hole-associated epiretinal proliferation and retinal changes during longterm follow-up. Br J Ophthalmol. 2018;102(1):84-90.

18. Parolini B, Schumann RG, Cereda MG, Haritoglou C, Pertile G. Lamellar macular hole: a clinicopathologic correlation of surgically excised epiretinal membranes. Invest Ophthalmol Vis Sci. 2011;52(12): 9074-9083.

19. Compera D, Entchev E, Haritoglou C, et al. Lamellar hole-associated epiretinal proliferation in comparison to epiretinal membranes of macular pseudoholes. Am J Ophthalmol. 2015;160(2):373-384.

20. Shiraga F, Takasu I, Fukuda K, et al. Modified vitreous surgery for symptomatic lamellar macular hole with epiretinal membrane containing macular pigment. Retina. 2013;33(6):1263-1269.

21. Sun JP, Chen SN, Chuang CC, et al. Surgical treatment of lamellar macular hole secondary to epiretinal membrane. Graefes Arch Clin Exp Ophthalmol. 2013;251(12):2681-2688.

22. Michalewska Z, Michalewski J, Odrobina D, et al. Surgical treatment of lamellar macular holes. Graefes Arch Clin Exp Ophthalmol. 2010; 248(10):1395-1400.
Clinical Ophthalmology

\section{Publish your work in this journal}

Clinical Ophthalmology is an international, peer-reviewed journal covering all subspecialties within ophthalmology. Key topics include: Optometry; Visual science; Pharmacology and drug therapy in eye diseases; Basic Sciences; Primary and Secondary eye care; Patient Safety and Quality of Care Improvements. This journal is indexed on Submit your manuscript here: http://www.dovepress.com/clinical-ophthalmology-journal

\section{Dovepress}

PubMed Central and CAS, and is the official journal of The Society of Clinical Ophthalmology (SCO). The manuscript management system is completely online and includes a very quick and fair peer-review system, which is all easy to use. Visit http://www.dovepress.com/ testimonials.php to read real quotes from published authors. 